\title{
Possible role of climate change in the pollen scatter of J apanese cedar Cryptomeria japonica in J apan
}

\author{
H. Teranishi ${ }^{1, *}$, Y. Kenda ${ }^{1}$, T. Katoh ${ }^{1}$, M. Kasuya ${ }^{1}$, E. O ura ${ }^{1}$, H. Taira ${ }^{2}$ \\ ${ }^{1}$ Department of Public Health, Faculty of Medicine, Toyama Medical and Pharmaceutical University, 2630 Sugitani, \\ Toyama 930-0194, J apan \\ ${ }^{2}$ Niigata University G raduate School of Science and Technology, Ikarashi, Niigata 950-2181, J apan
}

\begin{abstract}
We conducted an atmospheric pollen survey using a Durham sampler from 1983 through 1998 in Toyama City, J apan. We investigated yearly changes in the pollen season of J apanese cedar Cryptomeria japonica and analyzed the relationships between climatic factors and changes in the pollen counts. The results were as follows: (1) The first day of the Japanese cedar pollen season advanced from mid-M arch to late February. The yearly change in the first day was significantly associated with the mean temperature in February. (2) An increase in total pollen count was significantly associated with the mean temperature in the previous J uly. (3) The duration of the pollen season was suggested to be associated with the total pollen count. These results indicate that climate change, especially increasing global warming, influences the early pollen scatter and increase in pollen count as well as elongation of pollen season of J apanese cedar. Further study will be needed to clarify its effect on the health of pollen-allergy patients.
\end{abstract}

KEY WORDS: Dispersal $\cdot \mathrm{J}$ apanese cedar $\cdot$ Climate change $\cdot$ Pollen allergy

\section{INTRODUCTION}

Recently, an increase in the prevalence of pollen allergy to J apanese cedar Cryptomeria japonica D. Don has become one of the most important health problems in J apan. M any patients suffer from sneezing, nasal discharge, nasal congestion and ocular irritation during the period from February to April (Horiguchi \& Saito 1964, Ishizaki et al. 1987). As the pollen allergy is essentially influenced by the atmospheric pollen count, we studied the atmospheric pollen in Toyama City on the J apan Sea coast of Honshu from 1983 through 1998 in the corresponding pollen seasons.

In the present study we focused on the recent yearly change in the pollen season of J apanese cedar, especially as regards the influences of climate change.

*E-mail: hiterani@ms.toyama-mpu.ac.jp

\section{MATERIALS AND METHODS}

The atmospheric pollen survey was carried out on the roof of Toyama Medical and Pharmaceutical University in Toyama City $\left(36^{\circ} 40^{\prime} \mathrm{N}, 137^{\circ} 07^{\prime} \mathrm{E}\right)$ by Durham's gravity method (Durham 1946). The slides, coated with white vaseline, were collected daily at about 09:00 $\mathrm{h}$ and mounted in glycerine jelly containing $0.002 \%$ methyl violet (M erck, Germany). Pollen on the slide were counted under a light microscope. The first day of the J apanese cedar pollen season was designated as the day on which 3 or more pollen grains $\mathrm{cm}^{-2}$ were counted for the first time after the J anuary 1 , or the first day that 1 grain $\mathrm{cm}^{-2}$ was counted for 3 or more consecutive days after J anuary 1 . The end of the pollen season was defined as the last day on which 2 or less pollen grains $\mathrm{cm}^{-2}$ were counted. The climatic data were obtained from Fushiki meteorological station located $15 \mathrm{~km}$ from the atmospheric pollen sampling site. 


\section{RESULTS}

Fig. 1 shows the yearly change in pollen season from 1983 through 1998. The pollen season commonly begins in early $M$ arch, lasts nearly 2 mo and ends in late A pril. Yearly change in the pollen seasons showed a tendency to advance from 1983 to 1998. In particular, the tendency is marked in the period from 1989 to 1998 compared with the previous years, 1983 to 1988.

The yearly change in the beginning of the pollen season is shown in Fig. 2. The first day was clearly advanced from the 73rd day in 1983 to the 56th day in 1998 , although other yearly fluctuations were also observed.

The yearly change in the total pollen count of J apanese cedar is shown in Fig. 3. The increase from 1983 to 1998 is obvious, although some other yearly fluctuations can also be observed. The long-term change in yearly average temperature showed that it had a tendency to increase. The yearly mean temperature rose from $13^{\circ} \mathrm{C}$ in 1900 to $14^{\circ} \mathrm{C}$ in 1998 .

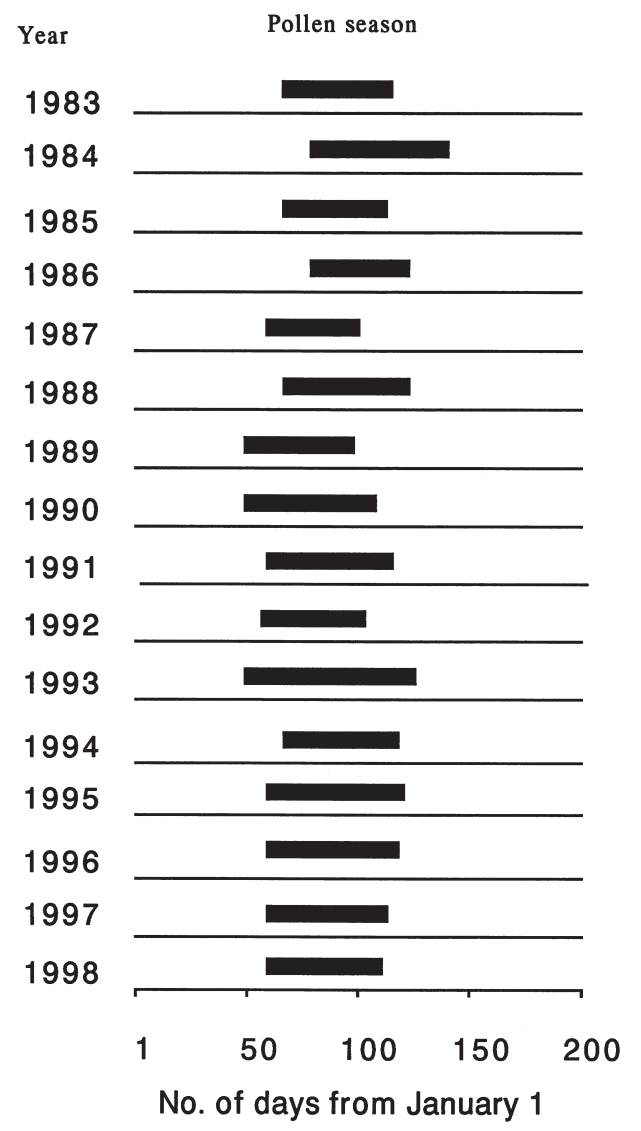

Fig. 1. Yearly change in pollen season of Japanese cedar Cryptomeria japonica from 1983 through 1998. Closed bars represent the J apanese cedar pollen season for each year: the first day, length and end of the pollen season
Fig. 4 shows the temperature changes in January, February and M arch from 1983 to 1998. The temperature change for the month of February was relatively marked, showing an approximate increase of $3^{\circ} \mathrm{C}$, from $2^{\circ} \mathrm{C}$ in 1983 to $5^{\circ} \mathrm{C}$ in 1998 . The significant relationship ( $r=0.91, p<0.001$ ) between the mean temperature in February and the first day of the pollen season is shown in Fig. 5.

Fig. 6 shows the significant relationship $(r=0.76, p<$ 0.001 ) between the mean temperature in the previous J uly and the total pollen count. This association means that the total pollen count increased in accordance with an elevated temperature in J uly of the previous year. Fig. 7 shows the relationship between the total pollen count and the duration of the pollen season. A significant association was suggested between these 2 variables $(r=0.484, p<0.10)$. That is, the duration of pollen season became longer as the yearly total pollen count increased.

\section{DISCUSSION}

In this study, we demonstrated that climate change, such as the increased warming temperature trends, affected the timing of the first day of the Japanese cedar pollen season. This early pollen scatter was shown to be closely associated with the elevated mean temperature in February.

After a pollen map and a pollen calendar were made for the J apanese archipelago (Nagano et al. 1978), several kinds of investigations were performed which demonstrated the effects of climatic conditions on the atmospheric pollen counts (Yamazaki et al. 1979, Taira et al. 1997). Kishikawa \& Nagano (1988) reported that the beginning of the $J$ apanese cedar pollen season correlated with the mean temperature in J anuary in Fukuoka City $\left(33^{\circ} 33^{\prime} \mathrm{N}, 130^{\circ} 27^{\prime} \mathrm{E}\right)$. In the same way, our study also demonstrated that the first day of pollen dispersal was closely correlated with the mean temperature of February. As Toyama is situated in the northern part of Honshu, far from Fukuoka in Kyushu, correlation with different months can be explained by the different latitudes of the 2 cities and the northward movement of the pollen front (Sahashi \& M urayama 1993).

Our study also demonstrated that an elevated temperature in the previous J uly had a causal effect on the total pollen count. Takahashi et al. (1996) reported that this significant increase in the total pollen count may be caused by global warming, using a simulation method in Yamagata City. In our study, interestingly, the data suggest that the total pollen count acts to elongate the pollen season. This effect might be partially explained by the fact that the number of days on which pollen is detectable increases in accordance with 
increases in the total pollen count. However, the diverse changes in pollen dispersal patterns caused by climatic changes, as well as related physiological alternations of J apanese cedar, cannot be neglected (Taira et al. 1998). As we performed the atmospheric pollen survey by the gravity method using a Durham sampler, further study using a volumetric sampler (Hirst 1952) is needed to clarify these effects.

No. of days from January 1

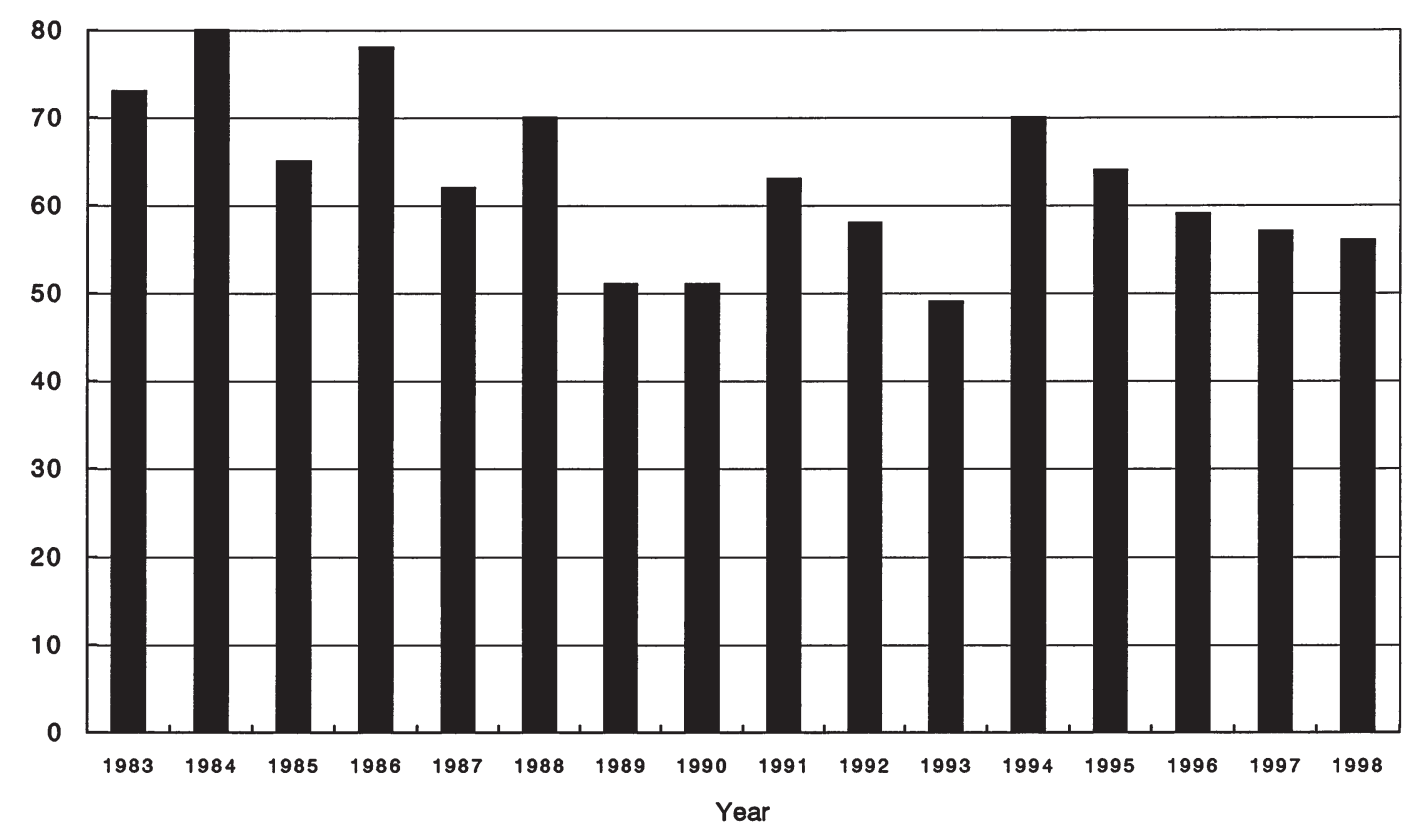

Fig. 2. Yearly change in the first day of J apanese cedar Cryptomeria japonica pollen season

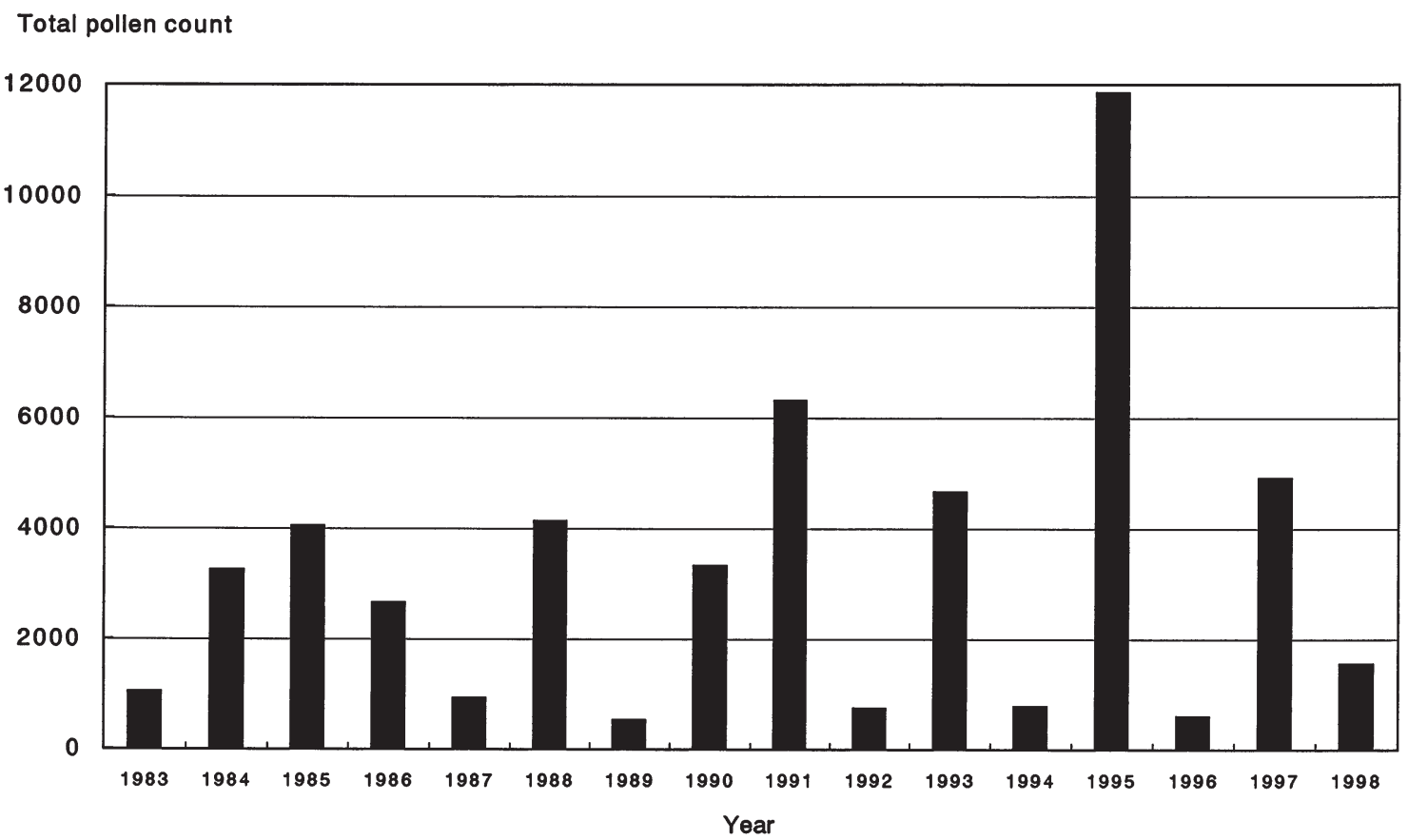

Fig. 3. Yearly change in total pollen count of J apanese cedar Cryptomeria japonica from 1983 through 1998 
Our study suggests that global warming is a probable cause not only for the earlier beginning of the pollen season but also the increase in total pollen counts, as well as a longer pollen season. These factors are considered to be closely related to the conditions to which people allergic to pollen are exposed and therefore their allergic

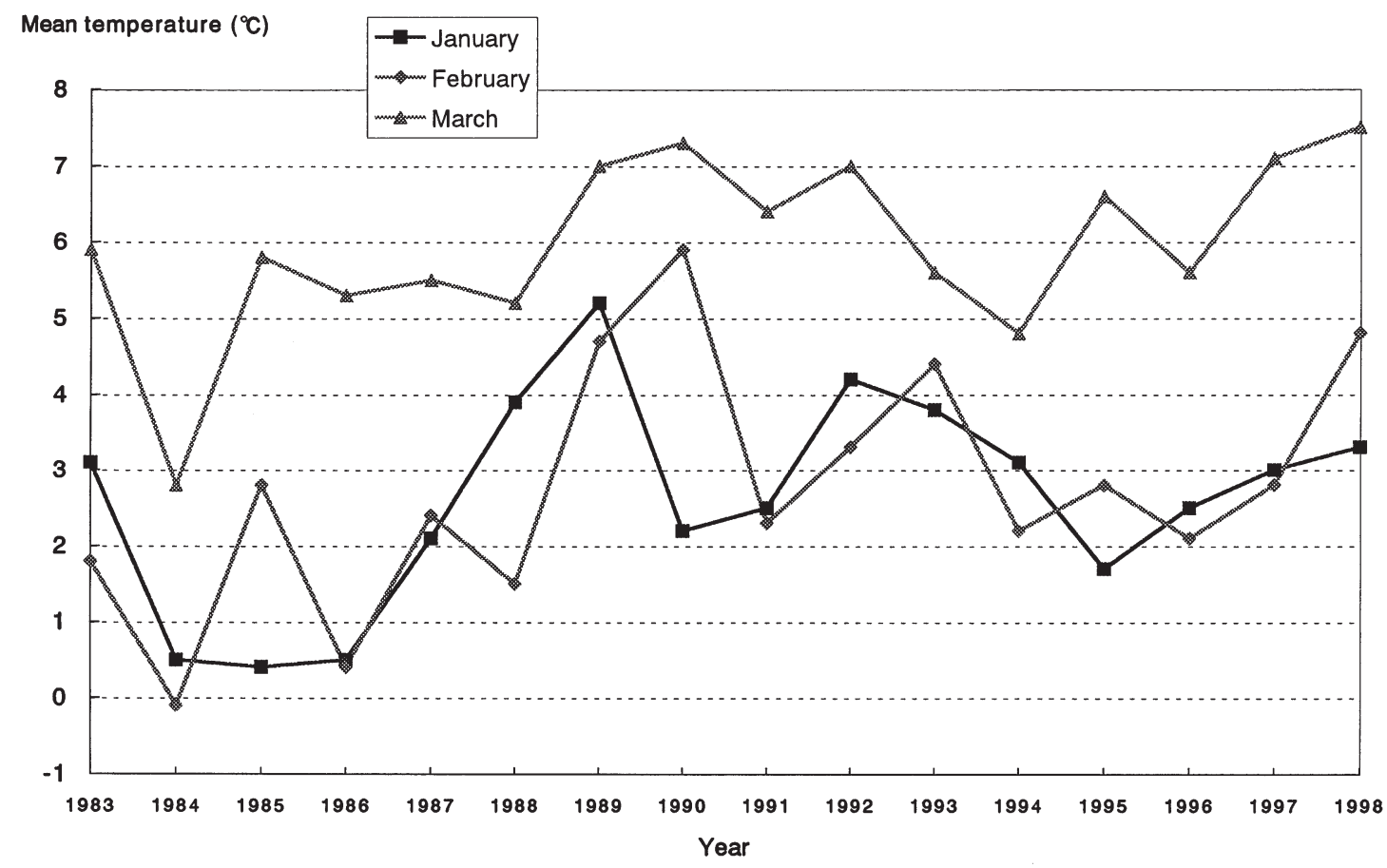

Fig. 4. Yearly changes in mean temperature in J anuary, February and M arch from 1983 through 1998

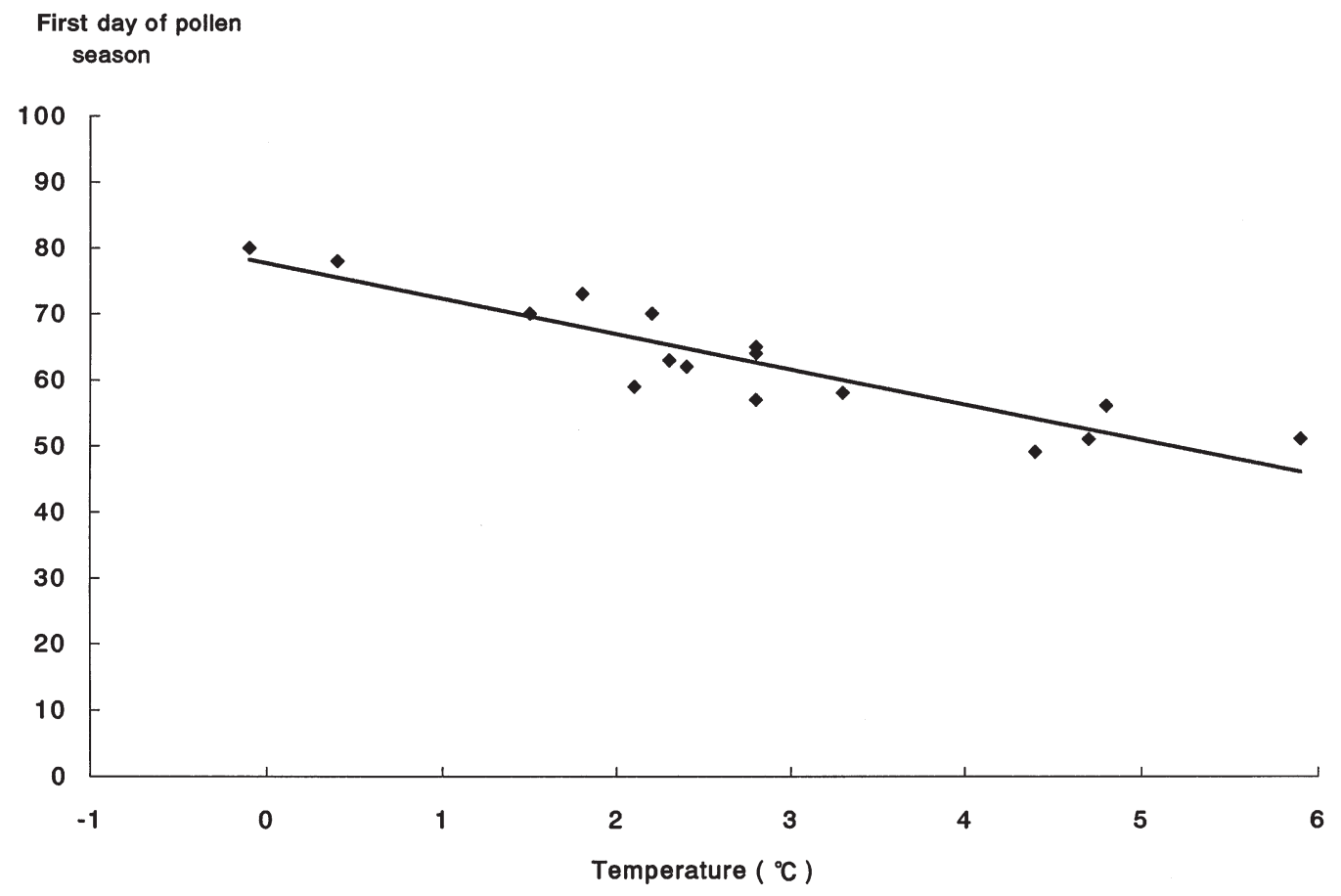

Fig. 5. Correlation between mean temperature in February and the first day of the J apanese cedar Cryptomeria japonica pollen season 
responses. In central J apan, a significant relationship between pollen count and the number of outpatients with a pollen allergy has been reported (Sahashi et al. 1990).
More precaution should be taken because the effect of global warming on atmospheric pollen impacts the general population and the public health.

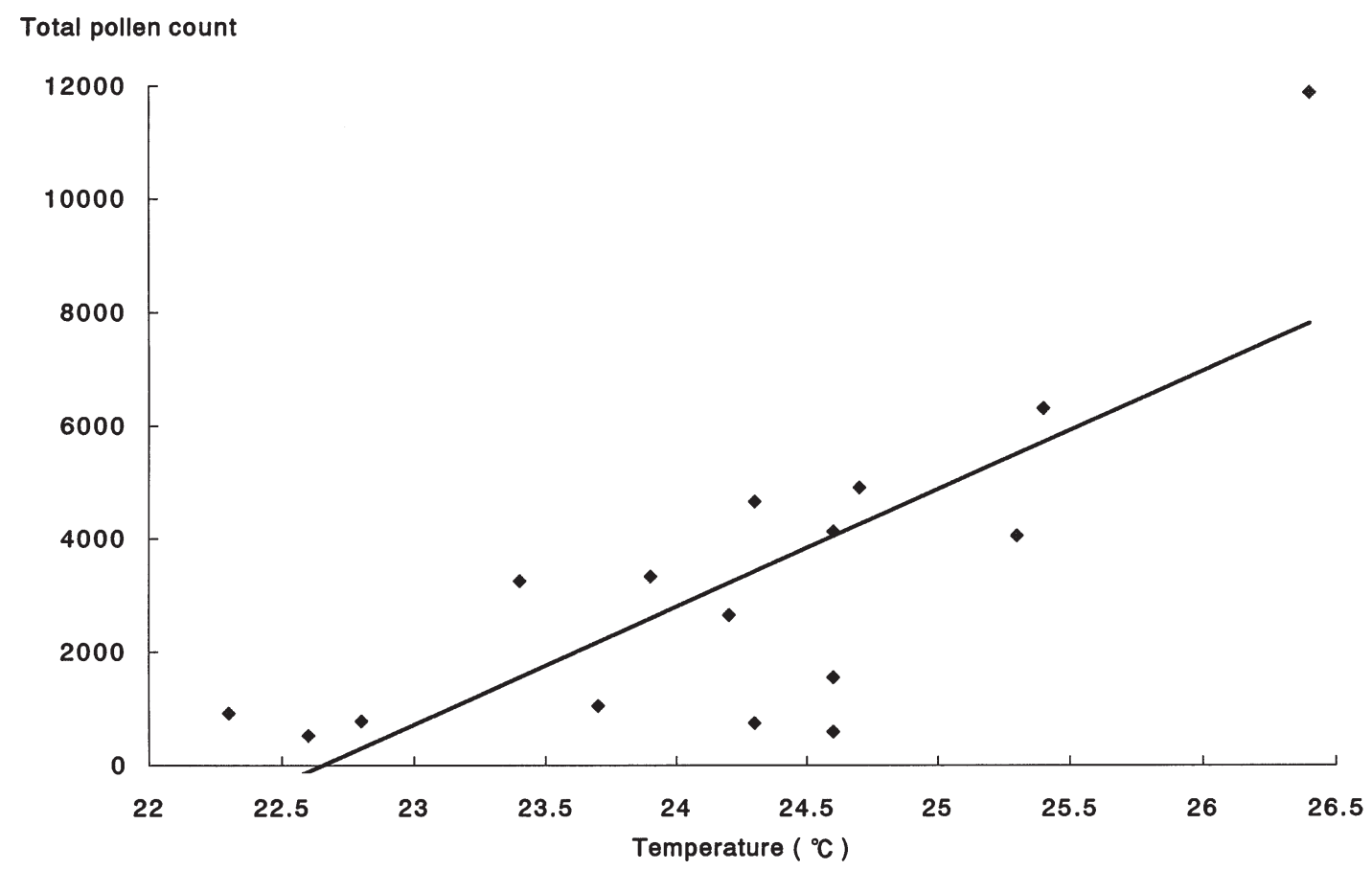

Fig. 6. Correlation between mean temperature in the previous J uly and total pollen count of J apanese cedar Cryptomeria japonica

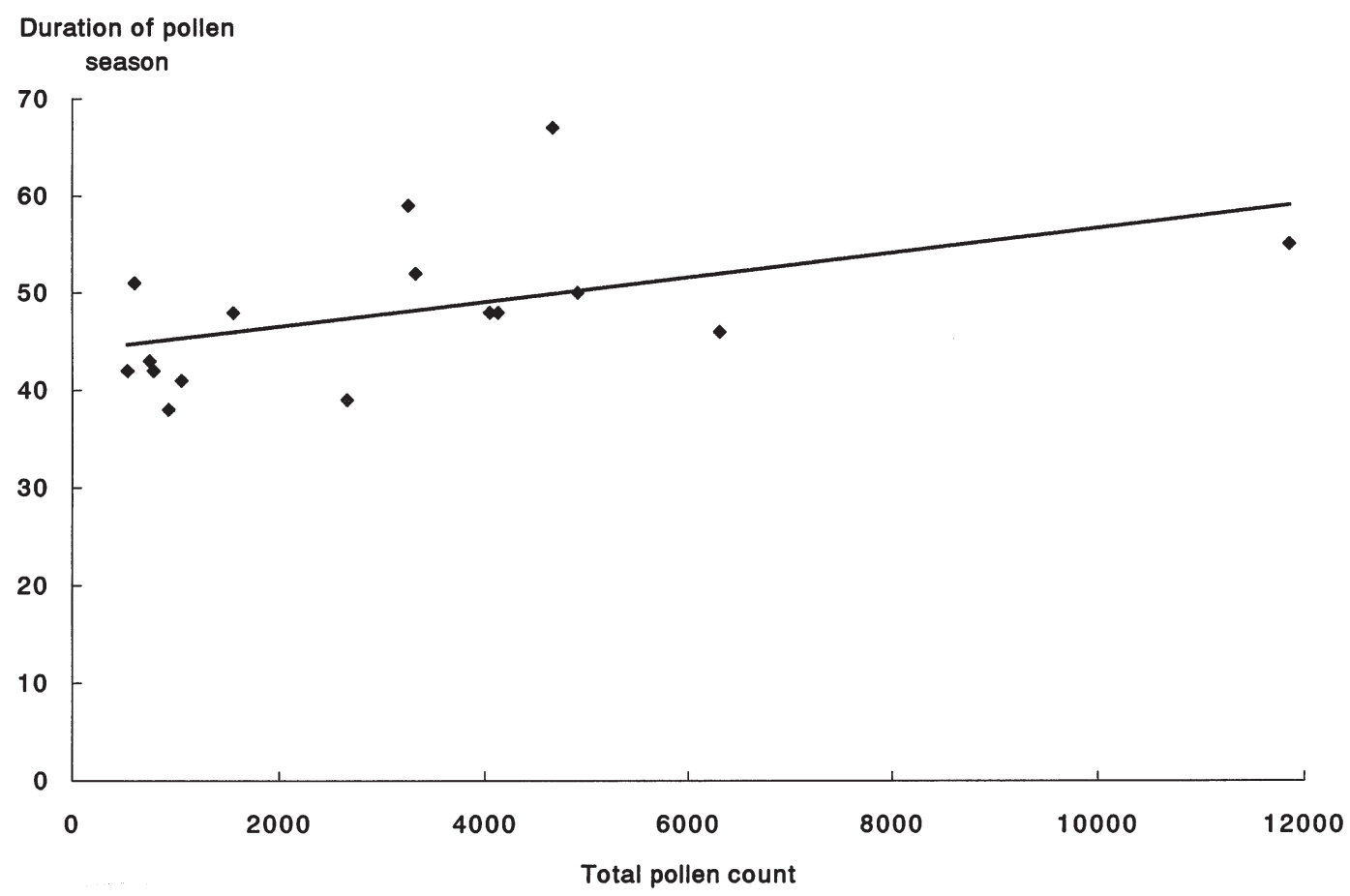

Fig. 7. Correlation between total pollen count and the duration of the pollen season of J apanese cedar Cryptomeria japonica 


\section{LITERATURE CITED}

Durham OC (1946) The volumetric incidence of atmospheric allergens IV. A proposed standard method of gravity sampling, counting and volumetric interpolation of results. J Allergy 17:79-86

Hirst J M (1952) An automatic volumetric spore trap. Ann Appl Biol 39:257-265

Horiguchi S, Saito Y (1964) J apanese cedar pollinosis in Nikko. J pn J Allergol 13:16-18 (in J apanese with English summary)

Ishizaki T, Koizumi K, Ikemori R, Ishiyama Y, Kushibiki E (1987) Studies of prevalence of J apanese cedar pollinosis among the residents in a densely cultivated area. Ann Allergy 58:265-270

Kishikawa R, Nagano H (1988) The annual variations in airborne Cryptomeria japonica and Cupressaceae pollen counts and meteorological conditions in Fukuoka City. J pn J Allergol 37:355-363 (in J apanese with English summary)

Nagano H, Katsuta M, Shida T (1978) Airborne pollen grains in the Japanese archipelago. Hokuryukan, Tokyo (in J apanese)

Sahashi N, Murayama K (1993) Change in the northward

Editorial responsibility: Mitsuru Ando,

Tsukuba, J apan movement of the pollen front of Cryptomeria japonica in J apan, during 1986-1991. Allergie Immunol 25:150-153

Sahashi M, Ikuse M, Ohmoto T, Saito Y, Takahashi Y, Takeda H (1990) Relationship between seasonal and annual total pollen counts of Cryptomeria japonica and Cupressaceae and number of outpatients with Sugi pollinosis in central J apan. Rev Palaeobot Palynol 64:79-86

Taira H, Teranishi H, Kenda Y (1997) Comparison of predictive methods of Sugi (Cryptomeria) atmospheric pollen counts using mean temperature, solar radiation and male flower index - an example of Toyama Prefecture. J pn J Allergol 46:489-495

Taira H, Teranishi H, Kenda Y (1998) The formation of pollen in male flowers and yearly atmospheric pollen counts of Cryptomeria japonica in the following year. Allergol Int 47:297-302

Takahashi Y, Kawashima S, Aikawa S (1996) Effect of global climate change on J apanese cedar pollen concentration in air. J pn J Allergol 45:1270-1276 (in J apanese with English summary)

Yamazaki F, Mizuno M, Shida T, Shimizu T (1979) Studies of pollen grains causative of pollinosis. I. On earlier prediction of pollen dispersion number of Cryptomeria japonica. J pn J Allergol 28:732-737 (in J apanese with English summary)

Submitted: October 1, 1999; Accepted: October 15, 1999 Proofs received from author(s): N ovember 30, 1999 